\title{
A significação contemporânea da efeméride
}

\author{
Prof. Doutor Vicente Marotta Rangel* \\ Diretor da Faculdade de Direito da Universidade \\ de São Paulo
}

No ato de celebração de mais um aniversário da instituição dos cursos jurídicos do país, em que esta Casa como a de Olinda são pioneiras, desejou-se celebrar - no contexto de simbolismo e de tradição das Arcadas - a solene posse do novo diretor. Profundamente comovido, almejo redizer palavras de agradecimento, que as proferi no dia 15 de julho último em cerimônia realizada na Reitoria da Uníversidade de São Paulo. Endereçam-se elas ao Magnífico Reitor, à Egrégia Congregação, a todos quantos - professores, alunos, funcionários, amigos, agremiados neste salão ou nele representados me têm distinguido com atos de apoio e confiança. A maneira mais adequada de exprimir a todos o meu reconhecimento é convidar-vos a elevar o pensamento à comemoração da data gloriosa de 11 de agosto.

Não tanto expressão individual, o que se vai dizer se pretende testemunho coletivo de todos quantos tenhamos vínculo de afeto para com a Faculdade do Largo de São Francisco. Vínculo de afeto: eis o título abrangente que nos confere cidadania para com esta Casa. Não se trata de jus sanguinis ou de jus soli ainda que Âlvares de Azevedo houvesse tido o privilégio de nascer no próprio solo das Arcadas; nem tanto o jus laborandi a que se reportam alguns artigos de convenções internacionais; mas a cidadania conferida pelo jus affectionis. As palavras que se hão de dizer não deixariam cá e acolá, neste ou naquele contexto, de serem proferidas por todo colega e mestre que se assentam no doutoral, por todo componente desta sala que nunca deixou de amar a Faculdade. Escusem-me, pois, se nesta romagem espiritual de que estamos a participar, omita o nome dos que se encontrem vivos e me limite apenas a incluir os que como dissera Guimarães Rosa - se tornaram "encantados" e estão a perambular pelo vale do Estige. Seremos todos, através do humilde porta-voz, pedreiros do mesmo templo, autores do mesmo cântico, cantadores do mesmo coral, espectadores do mesmo sonho.

* Discurso de Posse como Diretor, dia 11-08-1982, em sessão solene de Congregação. 
Está a perpassar nesta sala, tocado pelo fascínio da efeméride, longo cortejo de etéreos e peregrinantes. Cuidemos atentamente de segui-lo. Tem ele à frente Gaio, Papiniano, Modestino, Ulpiano, e demais juristas eminentes de Roma, a que se sucedem, em plano mais modesto, os que, à frente de suas casas - coram populo - porfiavam por esclarecer dúvidas de pleitos. Circundam-nos jovens empenhados em ouvir-lhes ensinamentos. Anunciam e precedem, emergidas do século XII, as primeiras corporações universitárias. Lá está, pois, a de Bolonha, cujos membros carregam ora o dístico de Bononia mater studiorum, ora o lema que Ruy Barbosa invocava ao referir-se à nossa Casa: Bononia docet. Emparelhados por "doutores" que então como entre nós agora nem sempre indicam apenas titulados por concurso específico mas também, advogados em geral, (Stephen d'Irsay, Histoire des Universités, I, p. 85), eis que se colocam Irnerius, Acursio e demais glosadores, cultores do direito civil e do direito canônico, Graciano, os santos Ives de Chartres e Raimundo de Peñaforte.

É de vê-los a seguir, no fantástico desfile, envoltos em sombra quase tão distante quanto as de Bolonha, com D. Diniz a encabeçá-los, mestres e estudantes de Coimbra, entre os quais é possível divisar estudantes brasileiros, como os autorizados por D. Pedro I, no Decreto de 18 de fevereiro de 1823, a lá permanecerem desde que estivessem a cursar a Universidade, tal qual Honório Hermeto Carneiro Leão, que depois se galardoaria com o título de Marquês de Paraná. São ao todo mais de uma centena, dentre os quais sobressaem os dois estudantes fluminenses e quatro baianos, que para São Paulo se transferiram, os primeiros a colarem grau em nossa Academia, em 1831, entre os quais Manuel Vieira Tosta, depois Marquês de Muritiba, e Paulino José Soares de Sousa, depois Visconde de Uruguai.

Já mais próximo de nós, figura na romagem José Feliciano Fernandes Pinheiro, que mais tarde ostentaria o título de Visconde de São Leopoldo, em cuja homenagem se dedicou o imponente salão de relíquias históricas de nossa Faculdade. Parece estar ele a propor, como o fizera na sessão de 14 de junho de 1823, a instalação de duas universidades, em Olinda e em São Paulo, e para aqui, de imediato, um curso jurídico. Presente está ainda Francisco de Paula Sousa e Melo cuja proposta de criação de cursos jurídicos em ambas as cidades, acabou por prevalecer na sessão de 1826, e deu origem à lei referendada pelo citado Visconde a 11 de agosto de 1827, cujo aniversário estamos a celebrar, o qual se poderia mesmo confundir-se com o aniversário de consolidação da pátria brasileira, pois não estaria "completa ainda a independência intelectual do Brasil, quando em 1822, ele afirmou a sua independência política", de vez que "faltava a criação dos cursos jurídicos", aos quais coube, no dizer de Clóvis Bevilaqua, "a missão nobre, entre todas, de derramar a instrução superior e fortalecer a brasileira."

Eis a participarem do desfile fantástico vultos de mestres, desde o primeiro a proferir a primeira aula de direito em nosso país, José Maria Avelar Brotero que, diplomado bacharel por Coimbra em 1819 
e doutor por esta Faculdade em 1831, nela professou ao longo do curso de quarenta e quatro anos. Estamos a vê-lo a proferir a aula inaugural, na sala $n^{\circ} 2$, a primeiro de março de 1828, no antigo Convento de São Francisco, após ter o diretor Arouche Rendon, ao abrir a sessão, se reportado ao significado da solenidade. Entre os numerosos docentes se divisam Veiga Cabral, Amaral Gurgel, Pires da Motta, Silveira da Motta, Chrispiniano, o Barão de Ramalho, Silva Carrão, Martim Francisco e José Bonifácio de Andrada e Silva, Ribas, Justino, Sá e Benevides, Leôncio Carvalho, Dutra Rodrigues. . Ao aproximar-se deste século, as fisionomias se mostram mais nítidas como as de Dutra Rodrigues, João Monteiro, Mamede, Brasiliense, Dino Bueno, Brasílio Machado, Oliveira Escorel, João Mendes, Almeida Nogueira, Herculano de Freitas, Carvalho de Mendonça, Cardoso de Mello, Pinto Ferraz, Aureliano Coutinho, Villaboim, Raphael Correia, Ulpiano de Souza, Cândido Motta, Veiga Filho, Camargo Aranha, Gabriel Resende, Reynaldo Porchat, Dario Ribeiro, Oliveira Coutinho.. O séquito dos diretores é longo, encabeçado por Arouche Rendon - não apenas tenente-general senão também doutor em leis por Coimbra. Seriam ao todo trinta e um se alguns dentre eles, os mais recentes, não estivessem felizmente, ainda agora, a integrar o doutoral, em nossa frente. É com especial enlevo que desde já os reverencio pois não tardarei a acompanhá-los na compassada e incorpórea marcha.

Ao longo do préstito invulgar bimbalham os mesmos sinos que conclamavam do coruchéu os moços para as aulas, como o fizeram na tarde molinhosa da inauguração do curso. Dia festivo esse, o de $1^{\circ}$ de março de 1828, "solenizado" - na frase de Arouche Rendon "com regozijo geral e com fatos demonstrativos de alegria pública", a que se seguiram três noites de iluminação espontânea, segundo informou o Farol Paulistano. Vêm-se também à surdina risos brejeiros dos estudantes que carregam consigo os badalos desses sinos que roubaram...

Continuidade de tradição e continuidade de Justiça! Aí estão na infindável e intangivel procissão, aureolados de civismo, Rio Branco, Nabuco, Afonso Pena, Rodrigues Alves, Ruy Barbosa. Com a lira em punho, Álvares de Azevedo, Fagundes Varella, Castro Alves.

Também Teixeira de Freitas, Lafayette, Pimenta Bueno, Alfredo Valladão. Presidentes da República, Campos Sales, Rodrigues Alves, Afonso Pena. Filósofos, jurisconsultos, estadistas, artistas da palavra escrita e oral, todos a confundirem-se com a própria história das instituições e idéias do país.

Ao término da caravana, talvez o último a integrá-la, pois a precisamente um mês, a 11 de julho último, foi chamado por Deus, bem visível pois com seu sorriso de bondade e alegria, estamos a vê-lo, Francisco Emygdio Pereira Neto, cuja memória impõe-se-nos reverenciar, num ato de homenagem indeclinável e de saudade imensa. Antigo tesoureiro, zeloso funcionário da Academia, foi desde os tempos de aluno das Arcadas, modelo de dedicação ao trabalho e ao estudo, 
sem descurar ao mesmo tempo, dos valores do civismo a que já dera provas ao engajar-se, por ocasião do movimento constitucionalista de 1932, no Batalhão 14 de julho, composto somente de acadêmicos de direito, e que travou batalhas em Itararé, ao Sul do Estado. Chefe de família exemplar, cidadão boníssimo e prestante, estamos a vê-lo nessa sua devoção de auxiliar incansavelmente os necessitados, mormente os estudantes, num espírito de imitação de São Francisco, em cuja igreja, ao lado, diariamente freqüentava as missas, o único leigo a adentrar o Convento nos almoços de 4 de outubro em homenagem à memória do Poverello. Teria sido por sua vinculação estreita com as Arcadas ou por sua associação tão íntima com São Francisco, que a praça em frente foi algumas vezes também chamada de Largo Chico Emygdio? Advogado exímio, conselheiro da Ordem durante dez anos consecutivos, padrão de dignidade e patriotismo, estimado em profundidade por seus pares, indicado pela Congregação desta Casa para vaga de Ministro do Tribunal Federal de Recursos, e homenageado pela mesma Congregação com retrato pintado à óleo e colocado, ainda em vida, em posição de destaque no saguão deste primeiro andar, vigilante constante e amoroso das tradições acadêmicas, Santo Chico Emygdio, velai pelas Arcadas!

Ao lançar o olhar sobre o majestoso cortejo dos protagonistas da história da Academia, que passo a passo desfila à nossa frente, impõe-se-nos à memória a frase com que Alcântara Machado se referiu ao falecimento de Oscar Freire, para exclamar com o insigne mestre desta Casa: "Quantas coisas morreram com a morte desses homens!" Mas para exclamar também, em acréscimo: "Quantas coisas permaneceram vivas com a morte desses homens" Vivas permaneceram, redivivas ficaram, rutilantes e inquebrantáveis como diamantes, lições de amor à nossa terra e à nossa gente, de respeito às leis do país, de devoção à liberdade, de custo à Justiça. Prelecionadas tanto pela palavra como pelo exemplo, desde os primórdios da nação e desta mesma Academia, tais liçôes forjaram o patrimônio cívico, moral e cultural das gerações antecessoras e compõem a constelação de valores que devem nortear - este o maior significado do legado recebido - o comportamento e as decisões de nossa própria geração. Pobres daqueles privados desses ensinamentos e carentes desses valores, pois correm o risco - tantas vezes infelizmente enfrentando não apenas de descumpri-los mas de permanecerem errantes como nautas sem bússola perdidos na imensidão do mar.

De tais ensinamentos se colhe a noção de crença no aprimoramento das instituições jurídicas através da história, fruto do reiterado esforço de gerações. Dissera-o Aureliano Coutinho em aula inaugural de 1896, ao apontar "essa continuidade do movimento progressivo, tendo como derradeira meta ou como ideal a realizar o predomínio da Justiça sobre a força, isto é, a vitória da liberdade". "Essas histórias da Justiça, lentas, porém certas, traduzem na história o direito ou o encaram num resultado sublime: a paz. A paz entre os indivíduos, por meio do respeito devido à sua personalidade; a paz entre 
as naçōes, por meio do respeito consagrado à sua autonomia: eis o primado do direito como um ideal que o progresso da civilizaçå̉o tende a realizar. Bem razão - aduzia o saudoso Mestre - tinha, pois, o profeta Isaías, quando proclamava que a paz seria o fruto da Justiça: Et erit opus justitiae pax." Graças a preceitos como esses que se reiteram na Academia em cujo patrimônio cultural e cívico se integram, é-nos possivel contemplar, com orgulho, essa constante busca da Justiça no plano interno e internacional, da qual advém o culto do país aos postulados do direito. Se esse culto é transgredido - e o tem sido, infelizmente - ou bem porque o transgressor não adentrou o templo desta ou de outras Academias do país, ou bem porque renegou os postulados de seus mestres.

A contribuição desta Casa na preservação e aprimoramento de ordem jurídica interna é notória através da atuação impertérrita dos seus antigos alunos, advogados e promotores assim como dos magistrados, garantias do respeito à lei, guardiões benfazejos da Justiça. Homenagens que se tributem, como o fazemos reverentemente neste momento, ao Poder Judiciário, ao Ministério Público, à Ordem, Instituto e Associação dos Advogados, a todos os poderes e instituições representativos da categoria de juristas, se estendem de certo modo a nossa Alma Mater, orgulhosa da sua progênie espiritual.

Beneficiada tem sido também a ordem jurídica internacional à medida que a Faculdade se mostrou paladina do recurso aos meios pacíficos, e seus ensinamentos concorreram para a delimitação pacífica de nossas fronteiras, num processo de rigoroso cumprimento do direito que tem suscitado em todos os países expressões de aplauso e admiração. No mês de outubro de 1907, Rio Branco visitou a sua antiga Escola e na sessão solene realizada então pelo Centro Acadêmico XI de Agosto, Pedro Lessa ressaltou a importância da contribuição da diplomacia brasileira - em cujos quadros se têm distinguido ilustres bacharéis diplomados no Largo de São Francisco. Vale a pena recordar o que Pedro Lessa então assinalou: "há nas relações internacionais" - disse ele - "onde não são raras as mais vivas contradições entre as lamentáveis contingências da vida real e os ensinamentos augustos da doutrina, um ato ainda mais meritório e glorioso do que contribuir para a formação das normas de direito: é aplicar abnegadamente e em toda a sua pureza, os princípios que a ciência propaga e as regras cristalinas nos tratados e costumes; é ter a elevação moral necessária para abstrair dos interesses secundários e transitórios dos Estados.

Cabe também evocar, ainda a título exemplificativo, a menção de Reynaldo Porchat, ao saudar José León Suarez - o eminente jurista argentino - em sua visita a esta Faculdade, no término da primeira guerra mundial, a de "um sentimento superior que paira acima de todas as cousas e de todos os homens, o sentimento da justiça internacional, que se há de tomar praticamente o princípio direto do congraçamento das nações na Magna Civitas". Esta Cidade 
Magna, esta Cosmópolis como a chamava João Monteiro, ainda está em vias de ser juridicamente aprimorada, embora seja certo que seus princípios básicos já se encontram sedimentados no documento fundamental firmado ao término da segunda guerra mundial, a Carta das Nações Unidas, na qual se cristalizam as expectativas de toda a esperança humana. Não é apenas de esperança - com o risco de ser distante e falaz - o sentir suscitado pela marcha da romaria intangível, prossegue ante nossos olhos. É também o da consciência da necessidade de vencer os desafios que rondam cada geração, a nossa mais do que nenhuma. São eles vários e complexos. Cinjamo-nos aos mais imediatos, pelo menos os relacionados com as quatro funções da Universidade: a de ensinar, a de promover pesquisa, a de servir à comunidade e a de encontrar a sabedoria. Porque cada uma dessas funções está em crise.

A primeira delas, a mais antiga de todas, a de ensinar, nos conduz ao reconhecimento de uma realidade implacável, extensiva é certo a todos os domínios da Universidade, mas particularmente sensivei ao campo do direito. A crise do ensino se impõe ameaçadoramente. Resulta ela do progresso tecnológico que o tornaria acessível a todos os interessados, mercê da rápida edição e distribuição de livros e periódicos, da radiodifusão, da telecomunicação, dos discos, dos video-cassetes. Processada a difusão dos conhecimentos jurídicos fora dos quadros universitários, há quem proponha ou preveja a morte das Escolas de Direito, o desinteresse dos estudantes para a freqüência às aulas, a desnecessidade do sistema tradicional de ensino? Acertada a previsão? Inelutável a morte? Parece que a resposta poderia ser afirmativa se na verdade os docentes se limitarem a repetir o que consta dos livros e demais meios de divulgação e não buscarem, a partir das informações difundidas, aprofundar reflexos sobre elas, em conjunto com seus próprios discípulos. Este é de fato o caminho trilhado em universidades estrangeiras, onde não se trataria a rigor de cogitar da prevalência eventual do método dedutivo ou indutivo, do sistema do "case" ou do "problem", mas de um processo dinâmico em que a aula se torna viva e fecunda desde que, mercê de esforço prévio, conheçam os alunos as informações disponiveis para delas extrair, com a presença e orientação do mestre, inferências ricas de conteúdo. Ter-se-ia, por outro lado, que proclamar a morte da docência? Seria o caso de considerá-la mera reminiscência das universidades medievais? A resposta seria infelizmente afirmativa a menos que o docente não seja igualmente educador, não tenha o dom ou autoridade de imprimir em suas classes o sentido de sua experiência pessoal e não traga consigo a constelação de valores em função dos quais o conhecimento se converte em sabedoria. Admitir, pois, a freqüência livre, além de desestimular o esforço dos alunos, poderá importar na abdicação pelos professores de sua alta missão de educadores.

Poderá ela agravar também a angustiosa crise da cultura, que se alastra predominantemente em nosso país, a ignorância de nossa 
história, o desconhecimento dos problemas e das soluções que intentem resolvê-los, a carência de reflexos sobre o curso de nosso destino como país e como nação. Quem somos nós? Quais os valores que nos rodeiam? Como partir do passado e buscar — tal qual este com apoio nele desferida — os horizontes incertos do futuro? Templo e testemunha viva da história pátria, esta Casa exibe em seus corredores, pateos, salas, de modo tangente e visível, o fluxo dos acontecimentos e idéias que brotam do pretérito em demanda do provir. Repositório e viveiro da cultura brasileira, museu e ao mesmo tempo alavanca e dínamo do sistema vital das idéias de nossa época, eis a Academia do Largo de São Francisco. Dela ausentar-nos, de seus pateos e de suas salas de aula, significa recusar-nos a tomar conhecimento de nós próprios, da terra e da gente de que provimos e a que devemos servir.

A serviço da comunidade a que pertença situar-se a universidade, mormente esta Casa de Ensino. Seria injustiça increpá-la de omissão a tal dever. Como desconhecer, ao contrário, no valor e inestimável contribuição ao aprimoramento das instituições políticas do país, à consolidação da independência, à abolição da escravatura, à república, ao processo de reconstitucionalização, ao revigoramento perene e culto indeclinável aos valores da Justiça, Paz e da liberdade? É preciso, porém, alertar para os problemas cruciais dos nossos tempos, que batem à porta do próprio templo, corporificados no número infindável e crescente de pedintes de esmola, de enfermos do corpo e da alma, de crianças desprotegidas, e refletidas nas doenças da própria sociedade, cuja etiologia econômica política e moral demandam providências urgentes e decisivas. Servir à comunidade importa ir além do conhecimento, do ensino e das pesquisas no campo do direito e partir para soluções que a ciência jurídica poderá propiciar ou ajudar a fornecer, soluções que importa sejam concretas e vitais embasadas no alicerce de teorias enriquecidas de objetividade e de humanismo.

Servir à comunidade, é certo, porém dentro dos parâmetros e reclamos da hora que vivemos. Ora, estamos a vivê-la em função de diretrizes inadiáveis. Algumas delas se integram no contexto de todas as horas, desde os primórdios até o fim da história da civilização. Assim a que consiste no respeito à dignidade da pessoa humana, centro de irradiação e de convergência de todo o direito. Irreal, contingente, falaz o direito, qualquer que seja o seu ramo, o seu lugar, o seu tempo, os seus agentes, a sua causa, os seus fins, se não tiver como centro básico de referência o respeito à dignidade da pessoa humana. Diretrizes contemporâneas há que se condicionarem a circunstâncias. Tal o é o da abertura do processo democrático já que visa não a realidades presentes mas a metas alviçareiras a atingir. Permitam-me proclamar a minha fé não apenas na abertura desse processo mas na necessidade de impulsioná-lo e apressá-lo. O país reclama democracia, não a meramente formal, porém a concreta e substantiva, provada na realidade de cada dia. Não a democracia das palavras, desmentida pela corrupção e pelo aventureirismo, mas a emergida 
da reforma das normas e estruturas, e aperfeiçoada cotidianamente na perseguição incansável do bem comum.

Objetivar tais metas na alvorada dos dias próximos importa na convocação dos jovens universitários das Arcadas para a integração em obras comuns, em espirito de respeito mútuo e de solidariedade. Essa integração deflui com naturalidade pois as gerações sucessivas da Academia se irmanam reciprocamente no culto convergente dos valores da liberdade da democracia e do direito. Não será suave a execução dessas tarefas a começar da excessiva abstração do conceito de Estado de Direito, "levado a um extremo formalismo dada a necessidade de enfrentar a complexidade sócio-política crescente", grau de abstração esse que, como diz Tercio Sampaio Ferraz Júnior, ao têrmino de seu livro sobre Fundação Social da Dogmática (1978), págs. $201 / 202$, "gera novos problemas, pois o conceito perde a sua funcionalidade, deixando de ser critério para a atuação do Estado na medida em que a sua conceituação formal deixa em aberto inúmeros problemas que apenas ampliam o papel do arbítrio, sem que a Dogmática forneça os parâmetros de controle".

Aprisionar disciplinas jurídicas em compartimentos estanques importa em negação do espírito científico e desconhecimento da natureza do direito. Identificar e robustecer os vínculos das disciplinas entre si assim como os dos respectivos cultores é inspiração de sabedoria a que o jurista não poderá furtar-se. Será nosso dever impulsionar estudos de questões contemporâneas mercê de conjugação inter-disciplinar de especialistas que se proponham promovê-los. Experiência fecunda - de que participamos na Coordenadoria de Atividades Culturais - suscitada pelo Departamento de Direito Penal constituirá inspiração de outras que intentaremos promover, sobretudo com a expectativa - para nós honrosa e alviçareira - de contar com a colaboração, sempre inestimável, de colegas de demais unidades de ensino e pesquisa da universidade. É certo que o conhecimento científico reclama especialização, mas é verdade também que ela não pode prescindir das sínteses finais, da visão de conjunto das cousas e das causas, da compreensão humanista do mistério dos seres.

O homem real e concreto é, em toda parte, um ser social que com seus irmãos partilha seus problemas. Toda vez que se isolar pretendendo bastar-se no seu narcisismo orgulhoso, tombará da dignidade de sua natureza. A Faculdade de Direito, revitalizada por seus vínculos com as demais unidades universitárias, dinamizará a sua imensa potencialidade no cultivo de sua própria tradição, no seu próprio enriquecimento interior através da convocação cívica e científica de seus docentes, estudantes, funcionários, antigos alunos e se debruçará, para ajudar a resolvê-los, sobre os magnos problemas de nosso paîs, e, entendendo que somente poderão ser equacionados mediante adequada inserção na sociedade brasileira, espera contar com a experiência e saber de todos os juristas, magistrados, advogados, promotores de Justiça. Ousará também, dentro do mesmo propósito de 
cooperação em escala cada vez maior, estimular intercâmbio com docentes e juristas de países irmãos.

Minhas Senhoras e Meus Senhores. A vossa honrosa presença nesta solenidade, sob a alta presidência do Magnífico Reitor, parece significar que esses propósitos poderão contar com o carinho de vossa compreensão, o incentivo de vossa inteligência e o calor da vossa afeição e do vosso carinho. A missão do novo diretor se torna assim extremamente suave e para ela gostaríamos de contar com a deferência de vossa constante participação. Missão outrossim discreta e exequível à medida que se dilui na perspectiva maior do culto festivo e glorioso do Direito. Missão singela e complementar pois decorrente do propósito básico de colimar a Justiça. Busquemos, em verdade, a Justiça, porque o resto - como o disse Goethe - o resto é conseqüência. 